\title{
Clinicopathological Review Of Colorectal Cancer
}

\author{
Dodiyi-Manuel A. (Mbbs, Fwacs, ${ }^{1,}$ Wichendu P.N. (Mbbs, Fwacs) ${ }^{2}$ \\ (Department Of Surgery, University Of Port Harcourt Teaching Hospital)
}

\begin{abstract}
Background: Colorectal cancer is the third commonest cancer worldwide after cancer of the lungs and stomach in males and cancer of the breast and cervix in females.Surgical resection is the only treatment option with curative potential $^{8,9}$. Adjuvant therapy is effective in prolonging survival and reducing disease progression in patients with colorectal cancer ${ }^{10}$.

Patients And Methods: This is an 8 year retrospective study of all patients with colorectal cancer admitted into the University of Port Harcourt Teaching Hospital (UPTH) between $1^{\text {st }}$ January, 2008 to $31^{\text {st }}$ December, 2016. Relevant data were retrieved and analysed using Statistical Package for Social Sciences (SPSS) version 16. Results: Seventy cases were analysed. There were 38 males and 32 females making a male to female ratio of 1.2:1.

Their ages ranged from 23 to 82 with an average of $48.5 \pm 3.7$ years. The peak age was the $41-50$ age range.The duration of symptoms before presentation at the hospital ranged from 1 week to 6 years.Adenocarcinoma was the commonest histological type, found in 56 (80\%) followed by the mucinous carcinoma in 4 (5.7\%) patients. Sixty four $(91.4 \%)$ patients had surgical procedures done with abdominoperineal resection being the commonest and done in $18(25.7 \%)$ patients.Post operative complications were recorded in $16(22.9 \%)$ and 12 patients died giving a mortality rate of $17.1 \%$.

Conclusion: Colorectal cancers constitute a health burden in Port Harcourt with a significant number of cases seen in young people. Majority of the patients presented late and at advanced stages. Therefore, screening of high risk population, public enlightenment, early diagnosis and prompt treatment and follow up will reverse this trend.

keywords: Clinicopathological, Colorectal, Cancer
\end{abstract}

\section{Introduction}

Colorectal cancer is the third commonest cancer worldwide after cancer of the lungs and stomach in males and cancer of the breast and cervix in females ${ }^{1}$. There is a worldwide variation in incidence with the highest rates recorded in North America, Western Europe, Australia and New Zealand while low rates are found in Africa and Asia ${ }^{2,3}$. The relative infrequency in Black Africa has been attributed to the young age of the population, shorter transit time of faeces, high fibre diet and rarity of precancerous conditions such as familial adenomatous polyposis, Crohn's disease and ulcerative colitis ${ }^{1}$. Regardless of the variation in incidence, the molecular characteristics are the same globally, ${ }^{4,5}$. In sub Saharan Africa, the incidence of colorectal cancer which was considered low is increasing ${ }^{6}$ probably due to the westernization of the diet while in the developed worlds, there is declining incidence with good treatment outcome attributable to early detection and presentation with advances in modalities of diagnosis and treatment ${ }^{7}$.

Surgical resection is the only treatment option with curative potential ${ }^{8,9}$. Adjuvant therapy is effective in prolonging survival and reducing disease progression in patients with colorectal cancer ${ }^{10}$

The aim of this study is to describe the clinicopathological pattern as seen in University of Port Harcourt Teaching Hospital.

\section{Patients And Methods}

This is an 8 year retrospective study of all patients with colorectal cancer admitted into the University of Port Harcourt Teaching Hospital between $1^{\text {st }}$ January, 2008 to $31^{\text {st }}$ December, 2016. Data which included age, sex, duration of symptoms before presentation at the hospital, family history of colorectal cancer, symptoms, site of the lesion, stage, grade, histology, macroscopic appearance, diagnostic modality, surgical procedure, post operative complications and outcome were retrieved from the case notes and analysed using SPSS version 16. Patient that signed against medical advice and those that died on arrival at the Accident and Emergency were excluded from the study. 


\section{Results}

During the study period, there were 76 cases of colorectal carcinoma. Six cases were not analysed because of incomplete records. Seventy cases were analysed. There were 38 males and 32 females making a male to female ratio of 1.2:1. Their ages ranged from 23 to 82 with an average of $48.5 \pm 3.7$ years. The peak age affectedwas the 41-50 age range. See table 1.There was a positive family history in 4(5.7\%) patients. Thirty eight $(54.3 \%)$ patients live in the rural communities while $32(45.7 \%)$ in urban areas.Twelve $(14.3 \%)$ patients did not have formal education while $16(22.8 \%), 24(34.3 \%)$ and $20(28.6 \%)$ of them had primary, secondary and tertiary levels of education respectively. The duration of symptoms before presentation at the hospital ranged from 1 week to 6 years. Sixteen (22.9\%) presented within 6 months of onset of symptoms, $12(17.1 \%)$ between 6 months and 1 year while $42(60 \%)$ patients between 6 months and 1 year. Table 2 shows the clinical presentation of the patients. The rectum was the commonest site of colorectal cancer, seen in $44(62.8 \%)$ of patients. The other involved sites are shown in table 3.Macroscopically, the predominant type in the rectum was malignant ulcer, seen in $24(34.3 \%)$ patients, followed by cauliflower in $16(22.8 \%)$ and annular constricting type in $4(5.7 \%)$ patients. The $6(8.6 \%)$ sigmoid colon, $4(5.7 \%)$ descending colon and $2(2.9 \%)$ of ascending colon tumors were of the annular constricting type while $8(11.4 \%)$ of the ascending colon and the $6(8.6 \%)$ caecaltumors were of the cauliflower type. Adenocarcinoma was the commonest histological type, found in 56 $(80 \%)$ followed by the mucinous carcinoma in 4 (5.7\%) patients. Two patients $(2.9 \%)$ each had malignant neuroendocrine tumor, squamous cell keratinizing and signet ring carcinomas. The majority of the tumors were well differentiated, seen in $36(51.4 \%)$ cases while moderately and poorly differentiated tumors seen in 24 $(34.3 \%)$ and $12(17.1 \%)$ cases respectively. According to the TNM staging, 34 (48.6\%) patients were in stage 4. The rest are shown in table 4.

Sixty four $(91.4 \%)$ patients had surgical procedures done. The remaining $6(8.6 \%)$ were unfit for surgery. Out of the 64 patients that had surgery, $56(80 \%)$ were operated upon electively while the remaining 8 $(11.4 \%)$ had emergency surgeries for intestinal obstruction in $6(8.6 \%)$ and appendicitis in $2(2.9 \%)$. Eighteen patients $(25.7 \%)$ had abdominoperineal resection and it was the commonest surgical procedure done. The rest are shown in table 5. Adjuvant chemotherapy was given to patients after surgery and chemotherapy alone given to the 6 patients that were unfit for surgery. Post operative complications were recorded in $16(22.9 \%)$. The post operative distribution is as shown in table 6. Twelve patients died giving a mortality rate of $17.1 \%$. The duration of follow up was from 2 months to 5 years. Data on long term survival was not available because most of the patients were lost to follow up.

Table 1: Age Range Distribution

\begin{tabular}{|c|c|}
\hline AGE RANGE & NUMBER OF PATIENTS (\%) \\
\hline $21-30$ & $8(11.4)$ \\
\hline $31-40$ & $14(20)$ \\
\hline $41-50$ & $20(28.6)$ \\
\hline $51-60$ & $8(11.4)$ \\
\hline $61-70$ & $10(14.3)$ \\
\hline $71-80$ & $8(11.4)$ \\
\hline $81-90$ & $2(2.9)$ \\
\hline
\end{tabular}

Table 2: Common Clinical Features

\begin{tabular}{|c|c|}
\hline FEATURE & NUMBER OF PATIENTS (\%) \\
\hline Diarrhoea & $8(11.4)$ \\
\hline Rectal bleeding & $34(48.6)$ \\
\hline Tenesmus & $14(20)$ \\
\hline Weight loss & $24(34.3)$ \\
\hline Abdominal mass & $18(25.7)$ \\
\hline Intestinal obstruction & $6(8.6)$ \\
\hline Rectal mass & $4(5.6)$ \\
\hline
\end{tabular}

Table 3: Sites Of Colorectal Cancer

\begin{tabular}{|l|c|}
\hline SITE & NUMBER OF PATIENTS (\%) \\
\hline Rectum & $44(62.8)$ \\
\hline Sigmoid colon & $6(8.6)$ \\
\hline Descending colon & $4(5.7)$ \\
\hline Transverse colon & 0 \\
\hline Ascending colon & $10(14.3)$ \\
\hline Caecum & $6(8.6)$ \\
\hline
\end{tabular}


Table 4: Tumor Node Metastasis (Tnm) Staging

\begin{tabular}{|c|c|}
\hline STAGE & NUMBER OF PATIENTS (\%) \\
\hline 1 & $10(14.3)$ \\
\hline 2 & $14(20)$ \\
\hline 3 & $12(17.1)$ \\
\hline 4 & $34(48.6)$ \\
\hline
\end{tabular}

Table 5: Surgical Procedure

\begin{tabular}{|c|c|}
\hline PROCEDURE & NUMBER OF PATIENTS (\%) \\
\hline Abdominoperineal resection & $18(25.7)$ \\
\hline Anterior resection & $6(8.6)$ \\
\hline Transverse colostomy & $6(8.6)$ \\
\hline Right hemicolectomy & $16(22.8)$ \\
\hline Sigmoid colostomy & $12(17.1)$ \\
\hline Left hemicolectomy & $2(2.9)$ \\
\hline Sigmoid colectomy & $4(5.7)$ \\
\hline Not fit for surgery & $6(8.6)$ \\
\hline
\end{tabular}

Table 6: Post Operative Complications

\begin{tabular}{|c|c|}
\hline COMPLICATIONS & NUMBER OF PATIENTS (\%) \\
\hline Surgical site infection & $6(8.6)$ \\
\hline Respiration infection & $6(8.6)$ \\
\hline Colostomy prolapse & $2(2.9)$ \\
\hline Colostomy diarrhoea & $2(2.9)$ \\
\hline
\end{tabular}

\section{Discussion}

Colorectal cancer has been described as one of the commonest causes of cancer related deaths in the western world ${ }^{11}$. Previously, it was thought to be rare among blacks and in patients up to 30 years of age and below ${ }^{12,13}$. However, recent observations indicate that the number of younger patients with colorectal cancer is increasing in Africa ${ }^{12,13}$. In our study, $31.4 \%$ of our patients were 30 years and below. The presence of a significant number of patients with colorectal cancer and the family history of $5.7 \%$ found in this study emphasizes the importance of family screening since genetic factors may play an important role in the development of the disease. This will lead to early detection and treatment.

Previous studies have demonstrated male preponderance in patients with colorectal cancer ${ }^{14-16}$. This was observed in our study where the incidence in males was slightly higher with a male to female ratio of 1.2:1. Though, there is no documented reason for this observation, it may be due to higher frequency of abdominal obesity, cigarette smoking and alcohol consumption in men.

Most of our patients (54.3\%) came from the rural areas located within the Niger Delta sub region but $62.9 \%$ of the patients had secondary education and above as opposed to some other studies ${ }^{17,18}$ where over $60 \%$ had either primary or no formal education. However, regardless of this relatively higher level of formal education seen in our study, there was no corresponding reflection in the time of presentation as most of our patients $(77.1 \%)$ presented late (after 6 months of onset of symptoms) with advance cancer $(65.7 \%$ in stages 3 and 4) which is in keeping with other studies in developing countries ${ }^{19,20}$. This late presentation may be attributed to lack of screening programme and religious/sociocultural beliefs as churches and spiritual homes are usually the first point of call in many cases..

Bleeding per rectum was the commonest presenting symptom which is in agreement with other findings ${ }^{21,22}$. It has been documented that rectal bleeding especially in older patient can be predictive of colorectal cancer especially when associated with abdominal pains or change in bowel habits ${ }^{23}$. Therefore, all cases of rectal bleeding should be properly investigated. There was preponderance of left sided lesions especially recto sigmoid $(71.4 \%)$ in this study which was similar to other reports. The correct diagnosis of colorectal cancer was made on the basis of clinical presentation including digital rectal examination, proctosigmoidoscopy, barium enema and during abdominal operations for other pathologies like intestinal obstruction and appendicitis. None of our patients had colonoscopy because of its unavailability in our centre. This experience is the same in most centres across Africa. Out of the 50 patients that had rectosigmoid cancers, only $24(48 \%)$ had resection surgeries (16 patients had abdominoperineal resection and 4 each anterior resection andsigmoid colectomy). This is comparable to the resection rate of $40 \%$ reported by Yawehet $\mathrm{al}^{22}$ from Maiduguri in Nigeria. This relatively low resection rate might be due to the late presentation with advanced stages of the disease.Morphologically, left sided (descending and sigmoid colon) tumors were more of annular constricting type while the right sided (ascending colon and caecum) cauliflower. This was similar to the findings of Abdulkareemet $\mathrm{al}^{24}$ and Chalya et al. The predominant histological type was adenocarcinoma which was seen in $80 \%$ of cases and well differentiated in $51.4 \%$. This finding concurs with that of other studies ${ }^{17,22}$ where similar histological patterns were reported. Sphincter saving procedures were not possible because the 
tumors were too low and advanced. However, early diagnosis and availability of stapling device in suitable cases will make sphincter saving procedures possible in our centre.

\section{Conclusion}

Colorectal cancers constitute a health burden in Port Harcourt with a significant number of cases seen in young people. Majority of the patients presented late and at advanced stages. Therefore, screening of high risk population, public enlightenment, early diagnosis and prompt treatment and follow up will reverse this trend.

\section{References}

[1]. Naaeder SB, Armah E, Tandoh JFK, Archampong EQ, Adu-Aryee NA, Ugwu BT, et al. Small and Large Intestine (Including Rectum and Anus). In: Archampong EQ, Naaeder SB, Ugwu BT. Eds. Principles and Practice of Surgery, $5^{\text {th }}$ edition. Ghana Publishing Corporation, Accra, 675-772.

[2]. Parkin DM, Pisani D, Ferlay J. Global cancer statistics 1999. CA Cancer J Clin 1999; 49: 33-64.

[3]. Jemal A, Bray F, Center MM, Ferlay J, Ward E, Forman D. Global cancer stastisics. CA Cancer J Clin 2011; 61: 69-90.

[4]. Adekunle OO, Abioye AA. Adenocarcinoma of the large bowels in Nigerians: a clinicopathological study. Dis Colon Rectum 1980; 23: 559-563.

[5]. Weitz J, Koch M, Debus J, Hohler T, Galle PR, Buchler MW. Colorectal Cancer. Lancet 2005; 365: 153-165.

[6]. Siegel R, Ward E, Brawley O, Jemal A. Cancer stastistics 2011; the impact of eliminating socio economic and racial disparities on premature cancer deaths. CA Cancer J Clin 2011; 61: 212-236.

[7]. Troisi RJ, Freedman AN, Devesa SS. Incidence of colorectal cancer in the United States: an update of trends bygender, race, age, subsite and stage, 1975-1994. Cancer 1999; 85: 1670-1676.

[8]. Popoola A, Ibrahim N, Omodele F, Igwilo I, Soyemi S. Clinico-pathological presentation of colorectal cancer seen in Lagos State University Teaching Hospital. Macedonian J Med Sci 2012; 5: 411-415.

[9]. Cunningham D, Atkin W, Lenz HZ, Lynch HT, Minsky B, Nordhinger B, et al. Colorectal cancer. Lancet 2010; 375 : $1030-1047$.

[10]. Allumv WH, et al. Cancer of the colon and rectum in the West Midlands 1957-1981. Br J Surg 1994; 81: 1060-1063.

[11]. Sule AZ, Mandong BM, Iya D. Malignant colorectal tumors: a ten year review in Jos, Nigeria. West Afr J Med 2001; 20: $251-255$.

[12]. Akinola DO, Arigbabo AO. Pattern and presentation of large bowel neoplasms in Nigerians. Cent Afr J Med 1994; 40: 98-102.

[13]. Ameh EA, Nmader PT. Colorectal adenocarcinoma in children and adolescents: a report of 8 patients from Zaria, Nigeria. West Afr J Med 2000; 19: 273-276.

[14]. Seleye-Fubara D, Gbobo I. Pathological study of colorectal carcinoma in adult Nigerians: a study of 45 cases. Nig J Med 2005; 14 : $167-172$

[15]. Edino ST, Mohammed AZ, Ochicha O. Characteristics of colorectal carcinoma in Kano, Nigeria: an analysis of 50 cases. Niger J Med 2005; 14: 161-166.

[16]. Fazeli MS, Adel MG, Lebaschi AH. Colorectal carcinoma: a retrospective, descriptive study of age, gender, stage and differentiation in Iran from 1995 to 2001 as observed in Tehran University. Dis Colon Rectum 2007; 50: 990-995.

[17]. Halya PL, Mchembe MD, Mabula JB, Rambau PF, Jaka H, Koy M, et al. Clinicopathological patterns and challenges of management of colorectal carcinoma in a resource limited setting: a Tanzanian experience. World J SurgOncol 2013; $11: 88$.

[18]. Ojo OS, Odesanmi WO, Akinola OO. The surgical pathology of colorectal carcinomas in Nigerians. Trop Gastroenterol 1992; 13: 64-69.

[19]. Adekunle OO, Abioye AA. Adenocarcinoma of the large bowel in Nigerians: a clinicopathological study. Dis Colon Rectum 1980; 23: 559-563.

[20]. Saidi H, Nyaim EO, Githaiga JW, Karuri D. Colorectal cancer surgery trends in Kenya, 1993-2005. World J Surg 2008; 32: 217223.

[21]. Saidi HS, Kanuri D, Nyaim EO. Correlation of clinical data, anatomical site and disease stage in colorectal cancer. East Afr Med J 2008; 85: 259-262

[22]. Yawe KT, Bakari AA, PidingaUH, Mayun AA. Clinicopathological pattern and challenges in the management of colorectal cancer in Sub Saharan Africa. J Chinese Clin Med 2007; 2:688-695.

[23]. Selvachandran S, Hodder R, Ballal M, Jones P, Cade D. Prediction of colorectal cancer by a patient consultation questionnaire and scoring system: a prospective study. Lancet 2002; 360: 278-283.

[24]. Abdulkareem FB, Abudu EK, Awolola NA, Elesha SO, Rotimi O, Akinde OR, etal. Colorectal carcinoma in Lagos and Shagamu, Southwest, Nigeria: a histopathological review. World J Gastroenterol 2008; 14: 6531-6535. 